\title{
IGREJA, INTELECTUAIS E 0 ESPAÇO DE PODER: PERFIS SOCIAIS E MODALIDADES DE ATUAÇÃO DE SACERDOTES NA POLITICA E NA CULTURA DO MARANHÃO (1950-1980)'
}

\section{CHURCH, INTELLECTUAL AND THE SPACE OF POWER: SOCIAL PROFILES AND MODALITIES FOR THE PERFORMANCE OF PRIESTS IN THE POLITICS AND CULTURE OF MARANHÃO (1950-1980)}

\author{
Hugo Freitas de Melo*
}

\section{Introdução}

0 processo de constituição de uma matriz híbrida e multifacetada de atuação de sacerdotes católicos, certificada institucionalmente a partir das novas diretrizes conciliares emanadas pelo Estado Pontifício do Vaticano, que culminou com a formação de dioceses em todas as capitais brasileiras pari passu com a "estadualização" do projeto de romanização posto em prática pela Santa Sé2, obteve contornos específıcos no Maranhão, particularmente no período que compreende as décadas de 1950 a 1980. Tem-se nesses decênios a emergência de condicionantes singulares que presidiram o processo de (re)defınição de papéis e posicionamentos sociais e institucionais de diferentes matizes assumidos pela Igreja Católica, cuja análise das dinâmicas locais permitiram o entendimento de suas configurações sociais num nível macrossociológico. Isso se tornou possível a partir do exame da própria reestruturação da instituição eclesiástica em todo o universo católico, entrecortada, de um lado, por lógicas exógenas que circunscrevem a atuação de bispos e sacerdotes num espectro de "enfrentamento dos problemas sociais” (MAINWARING, 2004, p. 25-26), e,

\footnotetext{
* Doutorando em Sociologia pela Universidade de São Paulo-USP (São Paulo/SP/BR). hugofreittas@ yahoo.com.br.

1. Artigo produzido a partir das contribuições em torno da discussão de um dos capítulos da minha dissertação de mestrado, intitulada $\mathbf{O}$ ofício de sacerdote: mediação cultural, atuação política e produção intelectual de padres no Maranhão, defendida junto ao PPGCSOC/UFMA, cujos resultados foram apresentadosna II Jornada Internacional de Ciências Sociais, realizada entre 13 e 16 de outubro de 2015, no Campus do Bacanga, UFMA, São Luís, Maranhão, pelas quais sou grato.
}

2. Entre outros, particularmente cf. Miceli (2009) e Azzi (2008). 
de outro, por dinâmicas endógenas ao âmbito eclesial que presidem e recondicionam o trabalho de salvação operado em novas bases doutrinárias e ideológicas (MICELI, 2009, p. 18-19).

Nessa perspectiva, que combina elementos de ordem estrutural e de aspectos subjetivos da ação dos agentes focalizados, identificados na conformação de um escopo ideológicodoutrinário centrado em bases institucionais que adquirem novos contornos a partir da elaboração de práticas evangelizadoras díspares, multidimensionais e plurais, o trabalho político e intelectual operado por sacerdotes católicos, num espaço periférico representado pelo Maranhão de meados do século XX, adquire uma dimensão significativa no processo de análise das estratégias e posicionamentos assumidos pela Igreja nos assuntos que transbordam e, ao mesmo tempo, redefinem as arenas de realização da atividade confessional, pulverizando fronteiras movediças e mal traçadas entre esferas sociais distintas, particularmente as da cultura e da política.

Dessa forma, o presente artigo pretende pontuar algumas dimensões de análise discutidas em um dos capítulos da minha dissertação (MELO, 2013), enfocando especialmente o exame dos recursos culturais e propriedades sociais adquiridos nos múltiplos espaços de socialização a que os agentes investigados estavam inseridos. Busca-se examinar o grau de acionamento e reconversão destes capitais para o âmbito da atividade política e da produção intelectual explicitados em perfis específicos de sacerdotes, exemplos flagrantes das configurações sociais que constrangem e delineiam os contornos do ofício sacerdotal no Maranhão. Contudo, antes de adentrar nas dimensões de análise evocadas, convém salientar alguns conceitos-chave mobilizados para a edificação do presente estudo.

\section{1. "Intelectuais" católicos e formas de mediação}

Constituídos como agentes intermediários culturalmente favorecidos e estabelecidos entre os grupos dirigentes e o "povo", exercendo a função de "porta-vozes", os "intelectuais" se diferenciam dos demais agentes no espaço de manipulação simbólica pelo desempenho de papéis que exprimem sua "capacidade de definir o social e de explicar as condições de sua organização" (PÉCAULT, 1990, p. 33). Nos primeiros decênios do século XX, estudos apontavam a relevância do trabalho desenvolvido pelos intelectuais no tocante à elaboração e organização das formas de pensar, observar e compreender os fenômenos sociopolíticos e culturais. Esse trabalho intelectual ficou ainda mais evidenciado na questão da formulação das bases teóricas do Estado Nacional, de onde se pôde depreender que os intelectuais, por sua capacidade social e culturalmente favorecida, possuíam uma "vocação" para elite dirigente, detentores de saberes e habilidades que os legitimavam para a "organização do político".

A partir da visada sociológica propiciada pelo arcabouço teórico-metodológico de Pierre Bourdieu, evidenciou-se que o trabalho de defınição e de nomeação das coisas do mundo social não se sustentava apenas pelo acúmulo de habilidades individuais e pela "intelectualidade" dos mediadores, mas primordialmente pela posição ocupada no espaço de poder mais amplo e pelo acúmulo de capitais raros e distintivos que permitiam aos agentes o acesso e a ocupação de tais posições. Como bem apontou Bourdieu (2008), o poder dos intelectuais que exercem a função de "porta-voz" depende de sua posição social no espaço de concorrência e não meramente do teor de seus escritos. Para esse autor, "o poder das 
palavras é apenas o poder delegado do porta-voz”, que enseja a observação de outras dimensões, como o reconhecimento e o desconhecimento, fatores estruturantes da delegação da autoridade da fala (e da escrita) e, por conseguinte, da produção e reprodução do discurso autorizado do porta-voz (BOURDIEU, 2008, p. 87-91).

Revestidos desses poderes sociais que sedimentam a autoridade delegada do portavoz e que, no estudo em questão, são combinados com o poder institucional eclesiástico que lhes recobre as vestes e os gestos, as práticas e as representações que produzem sobre o mundo social, os sacerdotes católicos instituem seus lugares de fala legitimada e autorizada por um tipo de reconhecimento (social, intelectual, político) advindo dos domínios exógenos à esfera religiosa. Essa heteronomia dos perfis sociais de agentes católicos, produtores de bens culturais, assenta-se nas suas múltiplas inscrições e associações (mais ou menos estáveis) tecidas e mantidas a partir do fluxo estabelecido com outras esferas sociais.

Daí pode-se entender que a atividade da escrita (consubstanciada na publicação de livros) exercida por esses agentes confıgura-se como fator de distinção, como atributo de "notoriedade" em relação aos demais agentes, como um tipo de capital amplamente valorizado no espaço em disputa à medida que o exercício de escrever é concebido como um dos principais atributos passíveis de reconhecimento intelectual (GRILL; REIS, 2012, p. 12), ao mesmo tempo em que se constitui e é reivindicado como recurso legítimo para a ocupação de determinadas posições e tomadas de posição no espaço de concorrência simbólica.

No que se refere à "formação da cultura” e da "organização do político" (PÉCAUT, 1990, p. 22), a observação das posições ocupadas pelos mediadores no momento de suas produções culturais, principalmente de escrita, é de fundamental importância para se compreender que seu poder de nomeação e de definição reside na combinação de seu trabalho intelectual com o reconhecimento social que lhe é conferido, isto é, na delegação da autoridade de onde provém seu discurso autorizado.

Essa imbricação entre cultura e política, efetuada pelo trabalho de mediação dos intelectuais, obteve como resultado por parte destes um estado de saída da teoria ao engajamento. Diversos estudos já enfatizaram que a passagem desses agentes do campo teórico para a práxis social se processou por meio da constituição e diferenciação de “modelos de intervenção”, espraiados para diferentes domínios e espaços sociais (REIS, 2010; SAPIRO, 2012; SEIDL, 2007; SIGAL, 2012). Gisèle Sapiro (2012) identifica algumas modalidades de intervenção dos intelectuais na política a partir do exame do caso francês, levando em conta o capital simbólico, a autonomia em relação às demandas externas e o grau de especialização dos agentes ${ }^{3}$. Para a autora, "os intelectuais ocupam uma posição dominada no seio das classes dominantes como detentores de um

3. Analisados numa perspectiva sócio-histórica e construídos de modo ideal-típico, Sapiro identifica e esmiúça oito tipos de intervenção política dos intelectuais: o intelectual crítico universalista; o guardião da ordem moralizador; o grupo intelectual contestador ou a "vanguarda"; o intelectual de instituição ou de organização política; o especialista consultado pelos dirigentes ou o "expert”; o intelectual crítico especializado ou o "intelectual específico"; e o grupo contestador especializado ou o "intelectual coletivo". 
capital cultural que se diferenciou do capital econômico com a institucionalização do sistema escolar" (SAPIR0, 2012, p. 22).

A partir desse entendimento, levandose em consideração que a emergência e a afırmação da figura do intelectual perpassam pelo processo de expansão do sistema escolar e pela institucionalização do ensino universitário no Brasil o que propiciou o surgimento de um mercado editorial interno e, simultaneamente, consumidor de bens simbólicos (SORÁ, 2010, p. 40-42) , os intelectuais são concebidos como produtores e agentes de circulação de noções comuns, concernentes à ordem social (SIGAL, 2012, p. 56). Fundamentando sua análise no contexto representado pela Argentina, Sigal assevera que os intelectuais são detentores de um saber que autoriza os investimentos no sentido de intervenção no mundo social, de onde parte para analisar o lugar dos intelectuais na política e o lugar do político para os intelectuais.

Convém observar, no entanto, que analisar os intelectuais enquanto "produtores de noções" numa dinâmica periférica, como a do Maranhão de meados do século $\mathrm{XX}$, implica ponderar o peso do capital cultural (formação escolar, títulos acadêmicos) associado com a posição social que ocupam no mercado de produção de bens simbólicos e com o capital de relações sociais de que gozam seus portadores. Isso acaba por revelar que, a nível local, o processo de definição e legitimação do intelectual, incluindo sua ramificação católica, ancora-se em vínculos de pertencimento a instâncias de consagração da atividade intelectual (academias de letras, institutos históricos e geográficos, universidades) combinados à inserção em círculos políticos e sociais privilegiados. Dito de outra forma, quanto mais próximo ou associado ao espaço de atividades político/burocráticas, tanto maior o grau de "intelectualidade" conferido aos produtores culturais (MELO, 2013, p. 84-86).

Além disso, as especificidades da atuação de sacerdotes no Maranhão, que apresentam uma gama de elementos e condicionantes exógenos ao universo religioso incidindo sobre sua intervenção intelectual no mundo social, apontam para a própria disputa pela definição do que é "ser intelectual". Tais observações ajudam a pensar que a participação de padres em espaços de socialização de letrados e literatos, por exemplo, se dá por conta das retribuições simbólicas advindas desses espaços como a conquista do reconhecimento de intelectual, o que justifica, em linhas gerais, a inserção de sacerdotes católicos nas academias de letras, universidades, institutos de pesquisa, jornais, bem como nos círculos de jornalistas, poetas, romancistas, historiadores e escritores maranhenses já estabelecidos.

Em verdade, não há como negligenciar duas dimensões analíticas fundamentais que evidenciam um menor grau de institucionalização do espaço religioso maranhense e, por isso mesmo, uma maior heteronomia da produção intelectual de padres dedicados à atividade da escrita e à publicação de livros: (i) a primeira diz respeito a uma maior valorização e importância das instâncias e dos critérios externos de consagração; (ii) e a outra, de um elevado grau de dependência da esfera política (CORADINI, 2003, p. 126).

Essa dependência se processa pelo desapossamento dos bens materiais que se constituem como impeditivos de primeira ordem à produção e veiculação de trabalhos escritos (contatos com editoras e editores) e suscitam a recorrência às redes de relações pessoalizadas de cada agente (bus- 
ca por apoios, patrocínios, financiadores e apadrinhamentos políticos) ${ }^{4}$. Em outras palavras, o "campo de produção cultural" analisado apresenta-se duplamente dominado pelo poder político e pelo poder econômico (posse dos bens materiais de produção), mediado por redes de relações sociais que acabam condicionando os assuntos abordados e limitando a inventividade dos escritores.

A somatória de tais fatores e condicionantes evidencia, pois, aquilo que Bourdieu (2004, p. 119) chamou de a "dissolução do religioso”, de onde provém a diversificação de ofertas de bens de salvação e a ampliação da produção de sentidos sobre o mundo social por clérigos católicos. Ancorados em elementos externos ao âmbito religioso, esses agentes engendram uma "redefinição dos limites" da esfera religiosa (BOURDIEU, 2004, p. 122), bem como uma ressignificação da própria atividade religiosa, ressaltando-se o intercruzamento entre as lógicas distintas de funcionamento nas esferas da política, da religião, da cultura e do social.

Desse modo, a intervenção de clérigos católicos nos espaços secularizados da política e da cultura, proveniente de uma tentativa de dominação ou de imposição dos princípios e regras religiosos sobre o mundo social, evidencia as "intersecções da esfera religiosa com o espaço universitário e intelectual e as formas de acúmulo da autoridade necessária ao exercício legítimo do papel de mediador socialmente reconhecido" (SEIDL, 2007, p. 80). Através do exame dos condicionantes que permitiram a afir- mação desses papéis por agentes católicos, o presente enfoque incide sobre a dimensão das condições sociais de pertencimento institucional desses "intelectuais católicos" e as articulações por eles tecidas com outros produtores culturais e instâncias exógenas ao mundo religioso, para fins de identificação e análise dos recursos acumulados e refratados para a esfera religiosa, possibilitando a constituição de "intérpretes culturais" (p. 81).

Com efeito, as perspectivas apresentadas até aqui evidenciam, em seu conjunto, a importância do trabalho intelectual realizado pelos mediadores, particularmente na defınição de papéis políticos, culturais e religiosos, observando-se, assim, a existência de uma espécie de complexificação da função de mediação. A análise dos capitais adquiridos, das posições ocupadas e dos trunfos mobilizados pelos sacerdotes investigados sinaliza para a exigência dessa atividade de "invenção das posições" e de papéis sociais cada vez mais um elevado grau de relativa especialização dos agentes responsáveis pela manipulação de bens simbólicos, de onde surge o poder dos intelectuais, os fundamentos de sua legitimidade e o estabelecimento de suas problemáticas como legítimas.

\section{Perfis sociais e múltiplos condicionantes de atuação religiosa}

Diante disso, passemos, então, ao exame de 14 perfis de sacerdotes investigados por sua atuação distintiva e exemplar das 
dimensões analíticas explanadas até aqui. Seus percursos de vida, postos ocupados, propriedades sociais e recursos culturais acumulados no decorrer do tempo, atrelados a concepções díspares sobre as novas doutrinas emanadas pela Santa Sé, os conduziram a moldar e espraiar sua atuação sacerdotal em esferas exógenas ao âmbito religioso, particularmente nos domínios da política e da cultura.

A explicitação dos dados a seguir mostra algumas das variáveis tomadas como pontos de análise e de composição do perfil social de agentes católicos que apresentam registros de atividade de escrita em suas carreiras religiosas, no período recortado (1950-1980). Parte-se da análise da formação escolar, dos títulos, da atuação profissional, dos trânsitos e reconhecimentos adquiridos em espaços sociais mais heterônomos, como esferas de atuação de letrados (faculdades, universidades, academias de letras, jornais, institutos de pesquisa), de participação política e de ação militante, além de dados gerais sobre as obras (ano de publicação, gêneros de escrita, temáticas etc.) para se estabelecer as relações sincrônica e diacrônica entre formação escolar e modalidades de escrita e entre posição social e produção intelectual no tocante às trajetórias dos padres investigados.
A escolha desse conjunto de agentes constituiu-se pela sua significativa e reconhecida atuação como mediadores culturais em distintas esferas, e pela consistência das propriedades sociais levantadas sobre os sacerdotes que, em determinados momentos de suas carreiras, se dedicaram à escrita como marco distintivo em relação aos demais agentes, como forma de luta política dentro dos espaços onde estavam inseridos, em consonância com a manutenção do sacerdócio. Assim, os casos arrolados são representativos das principais características que ajudam a compor a análise sobre as regularidades e as discrepâncias, aproximações e distanciamentos, entre registros sociais múltiplos e perfis sociais específicos base constitutiva da hibridização do ofício sacerdotal.

Compreende-se que as variáveis levantadas (idade de ordenação, nacionalidade, escolaridade, atividade profissional e instâncias de inserção) atendem à proposta de se analisar a delimitação dos tipos de engajamento incorporados pelos agentes, o seu âmbito de atuação, os tipos de investimentos feitos, os reconhecimentos obtidos e as posições ocupadas ao longo de seus trajetos, como forma de se explicitar os condicionantes que presidiram escolhas e caminhos trilhados e a relevância da atividade da escrita no desenvolvimento de suas carreiras religiosas. 
Quadro 1 - Algumas propriedades sociais dos 14 agentes investigados

\begin{tabular}{|c|c|c|c|c|}
\hline Padre & $\begin{array}{l}\text { Ano de } \\
\text { nascimento }\end{array}$ & $\begin{array}{l}\text { Idade/Ano } \\
\text { de ordenação }\end{array}$ & Nacionalidade/Origem & Formação superior \\
\hline Eider Furtado & 1916 & $\begin{array}{l}33 \\
(1949)\end{array}$ & Brasileiro/Viana-MA & Teologia, Filosofia \\
\hline $\begin{array}{l}\text { Clodomir Brandt e } \\
\text { Silva }\end{array}$ & 1917 & $\begin{array}{l}26 \\
(1943)\end{array}$ & Brasileiro/Colinas-MA & $\begin{array}{l}\text { Teologia, Filosofia, Huma- } \\
\text { nidades }\end{array}$ \\
\hline $\begin{array}{l}\text { Cônego Ribamar } \\
\text { Carvalho }\end{array}$ & 1923 & $\begin{array}{l}21 \\
(1944)\end{array}$ & Brasileiro/Codó-MA & Teologia, Filosofia \\
\hline João Mohana & 1925 & $\begin{array}{l}35 \\
(1960)\end{array}$ & Brasileiro/Bacabal-MA & $\begin{array}{l}\text { Medicina, Teologia, Filo- } \\
\text { sofia }\end{array}$ \\
\hline Alípio de Freitas & 1929 & $\begin{array}{l}24 \\
(1953)\end{array}$ & Português & Teologia, Filosofia, História \\
\hline Hélio Maranhão & 1930 & $\begin{array}{l}26 \\
(1956)\end{array}$ & $\begin{array}{l}\text { Brasileiro/Barra do } \\
\text { Corda-MA }\end{array}$ & Teologia, Filosofia \\
\hline Vito Milesi & 1931 & $\begin{array}{l}24 \\
(1955)\end{array}$ & Italiano & $\begin{array}{l}\text { Teologia, } \\
\text { Filosofia, Sociologia }\end{array}$ \\
\hline Xavier Gilles & 1935 & $\begin{array}{l}27 \\
(1962)\end{array}$ & Francês & Teologia, Filosofia, Direito \\
\hline Claudio Bergamaschi & 1937 & $\begin{array}{l}29 \\
(1966)\end{array}$ & Italiano & Teologia, Filosofia \\
\hline Victor Asselin & 1938 & $\begin{array}{l}26 \\
(1964)\end{array}$ & Canadense & $\begin{array}{l}\text { Letras, Teologia, Filosofia, } \\
\text { Sociologia, Direito, Mestra- } \\
\text { do em Teologia }\end{array}$ \\
\hline Carlo Ubbiali & 1939 & $\begin{array}{l}25 \\
(1964)\end{array}$ & Italiano & $\begin{array}{l}\text { Teologia, Filosofia, Antro- } \\
\text { pologia }\end{array}$ \\
\hline $\begin{array}{l}\text { Jean Marie-Van } \\
\text { Damme }\end{array}$ & 1947 & $\begin{array}{l}28 \\
(1975)\end{array}$ & Belga & $\begin{array}{l}\text { Teologia, Filosofia, Espe- } \\
\text { cialização em Educação de } \\
\text { Jovens e Adultos, Mestra- } \\
\text { do em Ciências Éticas e Re- } \\
\text { ligiosas }\end{array}$ \\
\hline Josimo Tavares & 1953 & $\begin{array}{l}26 \\
(1979)\end{array}$ & Brasileiro/Marabá-PA & Teologia, Filosofia \\
\hline Claudio Zannoni & 1953 & $\begin{array}{l}26 \\
(1979)\end{array}$ & Italiano & $\begin{array}{l}\text { Teologia, Filosofia, História, } \\
\text { Sociologia }\end{array}$ \\
\hline
\end{tabular}

Fonte: Dados coletados de fontes diversas. 
0 primeiro aspecto a ser salientado trata da idade e do ano de ordenação sacerdotal dos agentes. São homens que iniciaram sua vida clerical com idade variando de 21 a 35 anos. Dos casos pesquisados, 12/14 foram ordenados padres com menos de 30 anos, com média de idade de 25 anos. 0 mais jovem desses casos, com idade de entrada na esfera eclesiástica com 21 anos, diz respeito ao cônego Ribamar Carvalho, cuja atuação se concentrou no campo de produção intelectual, exercendo principalmente as atividades de escritor e professor universitário. Já o mais velho dos sacerdotes ordenados foi João Mohana, que se tornou padre aos 35 anos.

É interessante observar que a entrada de Mohana no mundo da Igreja de modo tardio em relação aos demais agentes investigados suscita o acúmulo de outras experiências vividas por ele, inclusive de formação profissional e de pertencimento a círculos sociais fora do âmbito religioso, como foi o seu caso, que se formou e atuou como médico e foi premiado a nível nacional por sua produção literária antes de se tornar padre. 0 conjunto de conhecimentos e reconhecimentos obtidos antes de sua ordenação, fora do mundo eclesiástico, foi acionado no transcorrer de sua carreira religiosa, levando-o à ocupação de posições relativamente bem alocadas no espaço religioso maranhense dentro de um campo de poder mais amplo.

Em relação ao ano de ordenação dos 14 casos analisados, tem-se variação entre as décadas de 1940 a 1970, com concentração nos anos de 1960 (5/14). Vivia-se neste período as ingerências do regime militar brasileiro e os auspícios das prerrogativas emanadas do Concílio Vaticano II (BEOZZO, 2005), condicionantes que, dentre outras coisas, influíram sobremaneira no engajamento militante de padres num contexto periférico como o Maranhão (MELO, 2010,
2013; PEREIRA, 2011; MACHAD0, 2012), uma vez que os padres recém-saídos dos seminários formavam uma espécie de plantel eclesiástico à disposição dos líderes da Igreja Católica, que os direcionavam para os locais onde a necessidade por sacerdotes era mais acentuada (MELO, 2010, p. 54).

No que concerne à nacionalidade dos agentes, tem-se 6/14 nascidos no Brasil e 8/14 com nascimento em território estrangeiro. Dos brasileiros, contam-se 5 maranhenses e 1 paraense. A concentração dos nascidos no Maranhão dá-se caracteristicamente no interior do estado (Bacabal, Colinas, Barra do Corda, Viana e Codó). Quanto aos estrangeiros, contam-se 4/8 italianos e 4/8 de distintas nacionalidades ( 1 canadense, 1 francês, 1 português, 1 belga).

A presença e atuação de padres estrangeiros no Maranhão no período estudado, tanto no engajamento militante em "causas sociais" quanto na dedicação à produção de representações católicas sobre o mundo social, sinaliza para um processo mais amplo de importação de sacerdotes sob a regência do Vaticano para países periféricos, onde a escassez de padres era mais sintomática. Números divulgados em pesquisa realizada anteriormente, foram apresentados aos católicos maranhenses no final da década de 1960, com os seguintes dados:

Dados sociológicos de 1955 revelam que a Igreja do Maranhão dispunha de 130 sacerdotes de ambos os cleros [regular e secular]: 67 eram brasileiros e 63 estrangeiros. Hoje, em 1968, há no Maranhão 212 sacerdotes seculares e religiosos, sendo 58 brasileiros e 154 estrangeiros ("JORNAL DO MARANHÃO”, apud MELO, 2010, p. 44).

Os dados evidenciam que a participação de padres estrangeiros na vida cultural do 
estado, particularmente na produção de livros, não está dissociada de um movimento macro de imigração de sacerdotes de diversas nacionalidades para o Maranhão, o que lhes confere outro aspecto distintivo em relação aos demais padres de origem nacional. 0 fato de dos 14 casos investigados, 8 ocuparem posições de destaque no cenário de produção escrita no estado revela, entre outros fatores, o peso relativo que as relações “centro/periferia” (CORADINI, 2012) conferem aos agentes "vindos de fora".

No que se refere ao nível de instrução superior, além dos estudos obrigatórios para o exercício do ofício de sacerdote (Filosofia e Teologia), 9/14 apresentam formação escolar diversificada. Deste montante, a predominância é do bacharelado em Sociologia (3), seguido pelos cursos de História (2) e Direito (2), além de Medicina (1), Letras (1), Antropologia (1) e "Humanidades" (1) - este último, referido com este nome nas fontes consultadas sobre a formação do padre Clodomir Brandt. Dos 9 casos que apresentam um capital cultural heterogêneo, 2 registram acúmulo de formação em Sociologia e Direito concomitantemente, o que explica a correspondência numérica entre a quantidade de agentes com múltipla formação superior (9) e o quantitativo de cursos preponderantes (5).

Nos testes realizados para se verificar se havia ou não correspondência entre as variáveis apresentadas, é possível observar algumas regularidades entre nacionalidade e diversificação da instrução superior. Dos 9 casos que apresentam formação além de Teologia e Filosofia, 2 são brasileiros e 7 estrangeiros.

Os padres de nacionalidade brasileira são os maranhenses João Mohana (bacharel em Medicina) e Clodomir Brandt (licenciado em "Humanidades" - curso apresentado pelas fontes consultadas como uma interdisciplinaridade entre História, Geografia e Letras). No caso dos padres estrangeiros (7) que se encaixam nesta formação escolar híbrida, 3 são italianos, 1 canadense, 1 francês, 1 português e 1 belga. Deste montante, predomina a formação em Sociologia (3), seguida pelo Direito (2), História (2) e Letras (1). A predominância de tais cursos é reveladora das definições do processo de aquisição de disposições em torno das modalidades de engajamento dos padres estrangeiros com formação multifacetada.

Não por acaso, os agentes que apresentam em seus registros biográficos participação em espaços de atuação mais próximos de um "perfil militante" possuem predominância de formação na área das ciências sociais e do Direito. Tal aspecto lhes favorece a inserção em novos espaços institucionalizados de evangelização, a partir dos usos das ciências humanas (CORADINI, 2012, p. 68-69) como trunfo legitimador de seu envolvimento nos debates públicos, duplamente autorizado pela Igreja e pela “ciência” (MELO, 2013, p. 150-162).

Pode-se depreender disso a tessitura de uma configuração na qual não é rara a utilização de determinados saberes por parte dos agentes, adquiridos de um modo geral em espaços de formação superior, na formulação de estratégias, práticas e intervenções sobre as dinâmicas do mundo social, sendo possivel correlacionar o uso desses conhecimentos com o acionamento de certas modalidades de engajamento (SAPIRO, 2012, p. 95). Em seu conjunto, tais condicionantes presidem as ações dos sacerdotes nas diferentes esferas das quais participam e que são, também por isso, valorizadas como pré-requisitos para a definição e ocupação de posições relativamente bem alocadas no espaço de poder mais amplo. 
Nesse sentido, os dados sobre a formação escolar dos casos elencados oferecem pistas significativas sobre o tipo de perfil de sacerdotes católicos que se dedicam em algum momento à atividade de escrita, indissociavelmente conectados às posições que ocupam e às causas que defendem. São estes casos que participam da organização de atividades concernentes ao âmbito de ação de instituições vinculadas à Igreja, onde a defesa de "causas sociais" se constitui em pauta legítima de reivindicação no repertório de mobilização tanto dos sacerdotes e leigos quanto da própria Igreja.

\section{A hibridização do ofício sacerdotal}

Sobre os registros profissionais desempenhados pelos agentes ao longo de seus itinerários, pontua-se uma profusão de profissões, funções e atividades que mantêm estreita relação com o universo de sua instrução superior, assim como a participação em outros espaços de socialização e de intervenção. Observa-se uma miscelânea de atividades exercidas por clérigos católicos que extrapolam o ambiente confessional, concernentes ao âmbito de atuação de médicos, advogados, jornalistas, professores e literatos.

Quadro 2 - Dados sobre a atuação profissional e a participação em distintos espaços de socialização e de intervenção dos 14 casos investigados

\begin{tabular}{|c|c|c|}
\hline $\begin{array}{l}\text { Atuação profissional, } \\
\text { funções e atividades }\end{array}$ & $\begin{array}{l}\text { Pertencimento a instâncias de con- } \\
\text { sagração intelectual }\end{array}$ & $\begin{array}{l}\text { Participação em outros espaços de so- } \\
\text { cialização }\end{array}$ \\
\hline $\begin{array}{l}\text { Médico, poeta, teatró- } \\
\text { logo, romancista, en- } \\
\text { saísta, professor, pes- } \\
\text { quisador }\end{array}$ & $\begin{array}{l}\text { Membro da AML (1970), Cadei- } \\
\text { ra No } 03\end{array}$ & $\begin{array}{l}\text { Fundador e presidente da Juventude } \\
\text { Universitária Autêntica Cristã (JUAC); } \\
\text { Presidente Arquidiocesano da Ação Ca- } \\
\text { tólica no Maranhão }\end{array}$ \\
\hline $\begin{array}{l}\text { Educador, teatrólogo, } \\
\text { romancista, ensaísta, } \\
\text { pesquisador, jornalista, } \\
\text { politico }\end{array}$ & $\begin{array}{l}\text { Editor dos jornais "Notícias" e “A } \\
\text { Cruzada Maranhense" }\end{array}$ & $\begin{array}{l}\text { Candidato à prefeitura de Arari (1959); } \\
\text { vereador por três mandatos (PSD); fun- } \\
\text { dador de escolas, teatros, jornais, pos- } \\
\text { tos de saúde }\end{array}$ \\
\hline $\begin{array}{l}\text { Professor, poeta, en- } \\
\text { saísta }\end{array}$ & $\begin{array}{l}\text { Professor do Seminário de San- } \\
\text { to Antônio; Sócio titular da Acade- } \\
\text { mia Barracordense de Letras (1997); } \\
\text { Membro da AML, Cadeira No } 21 \\
\text { (1998); Presidente da Academia de } \\
\text { Ciências, Artes e Letras de Tutoia } \\
\text { (2002), Cadeira No } 01\end{array}$ & $\begin{array}{l}\text { Fundador e organizador da CEB de Tu- } \\
\text { toia (1965); fundador de escolas, orga- } \\
\text { nizações sociais, movimentos rurais e } \\
\text { entidades religiosas; Assistente ecle- } \\
\text { sial da Juventude Universitária Católica } \\
\text { (JUC); primeiro Presidente do Instituto } \\
\text { de Colonização e Terras do Maranhão } \\
\text { - Iterma (1982); Capitão da Capelania } \\
\text { Militar do Maranhão desde } 1993\end{array}$ \\
\hline Professor, romancista & $\begin{array}{l}\text { Professor de Filosofia e Sociolo- } \\
\text { gia nos cursos de Direito, Pedago- } \\
\text { gia e Ciências Contábeis da UFMA } \\
\text { (1983-1994); fundador e Presidente } \\
\text { da Academia Imperatrizense de Le- } \\
\text { tras (1991-1999) }\end{array}$ & \\
\hline
\end{tabular}




\begin{tabular}{|c|c|c|}
\hline Professor, advogado & $\begin{array}{l}\text { Professor no Seminário de Santo } \\
\text { Antônio }\end{array}$ & $\begin{array}{l}\text { Coordenador Estadual das CEBs no Ma- } \\
\text { ranhão (1973-1975); Fundador da CPT } \\
\text { Nacional (1975); fundador e primei- } \\
\text { ro Presidente da CPT-MA (1976-1980); } \\
\text { Diretor da Cáritas-MA (1980); Chefe de } \\
\text { Gabinete na Prefeitura de Balsas (1995- } \\
\text { 2000); consultor da Secretaria de Segu- } \\
\text { rança do Governo Jackson Lago (2006- } \\
\text { 2009); formação de lideranças da Ju- } \\
\text { ventude Operária Católica (J0C); advo- } \\
\text { gado nas esferas do Direito Agrário e } \\
\text { do Direito Penal }\end{array}$ \\
\hline $\begin{array}{l}\text { Militar, professor, ad- } \\
\text { vogado }\end{array}$ & $\begin{array}{l}\text { Reitor do Seminário de Santo Antô- } \\
\text { nio (1989-1994), além de professor } \\
\text { da mesma instituição }\end{array}$ & $\begin{array}{l}\text { Assistente eclesial da JOC; Coordenador } \\
\text { Estadual da CPT e das CEBs do Mara- } \\
\text { nhão (1980-1982); advogado na esfera } \\
\text { do Direito do Trabalho }\end{array}$ \\
\hline Professor, jornalista & $\begin{array}{l}\text { Professor da Faculdade de Filosofia } \\
\text { do Maranhão; Professor de História } \\
\text { e Filosofia da Universidade do Ma- } \\
\text { ranhão (hoje UFMA) }\end{array}$ & $\begin{array}{l}\text { Escreveu para “Jornal do Povo" e “Jor- } \\
\text { nal do Maranhão”, além de ter sido edi- } \\
\text { tor do jornal das Ligas Camponesas, “A } \\
\text { Liga”; militante da Ação Operária Cató- } \\
\text { lica e da J0C; Membro do Secretariado } \\
\text { Nacional das Ligas Camponesas }\end{array}$ \\
\hline \multirow[t]{2}{*}{ Educador popular } & $\begin{array}{l}\text { Membro da Academia Vianense de } \\
\text { Letras, Cadeira No } 02\end{array}$ & $\begin{array}{l}\text { Organizador e militante da CEB de Via- } \\
\text { na }\end{array}$ \\
\hline & & $\begin{array}{l}\text { Coordenador Estadual da CPT-MA } \\
\text { (1982) }\end{array}$ \\
\hline Professor, pesquisador & $\begin{array}{l}\text { Fundador da Escola de Antropolo- } \\
\text { gia Aplicada à distância em São Lu- } \\
\text { ís-MA }\end{array}$ & $\begin{array}{l}\text { Fundador da CPT-MA (1976); Funda- } \\
\text { dor e primeiro Coordenador do Conse- } \\
\text { lho Indigenista Missionário (CIMI) do } \\
\text { Maranhão; Vice-Presidente Nacional } \\
\text { do CIMI }\end{array}$ \\
\hline $\begin{array}{l}\text { Professor, pesquisador, } \\
\text { educador popular }\end{array}$ & $\begin{array}{l}\text { Professor de Filosofia, História e So- } \\
\text { ciologia do Seminário de Santo An- } \\
\text { tônio }\end{array}$ & $\begin{array}{l}\text { Assessor teológico e educacional da } \\
\text { CPT-MA; } \\
\text { organizador da CEB do bairro do Anjo } \\
\text { da Guarda, em São Luís (1975); Educa- } \\
\text { dor popular da Associação da Saúde da } \\
\text { Periferia (ASP); Membro do Conselho } \\
\text { de Assistência Social do Maranhão } \\
\end{array}$ \\
\hline Professor, pesquisador & $\begin{array}{l}\text { Professor do Departamento de His- } \\
\text { tória da UFMA }\end{array}$ & $\begin{array}{l}\text { Coordenador Regional do CIMI-MA } \\
(1985-1993)\end{array}$ \\
\hline \multirow[t]{2}{*}{$\begin{array}{l}\text { Professor, jornalista, } \\
\text { poeta, romancista }\end{array}$} & $\begin{array}{l}\text { Diretor da Faculdade de Filosofia do } \\
\text { Maranhão (1957); Membro da AML } \\
\text { (1959), Cadeira No 19; Vice-Rei- } \\
\text { tor (1962-1966) e Reitor da Univer- } \\
\text { sidade do Maranhão (1963-1967 e } \\
\text { 1968-1972) }\end{array}$ & $\begin{array}{l}\text { Secretário de Educação do Governo } \\
\text { Newton Bello; Assistente eclesial da } \\
\text { JIC, JOC e JUC }\end{array}$ \\
\hline & & $\begin{array}{l}\text { Coordenador da CPT-G0 (1979); mili- } \\
\text { tante nas questões de conflitos de terras } \\
\text { no Maranhão }\end{array}$ \\
\hline
\end{tabular}

Fonte: Dados coletados de fontes diversas. 
Dos 14 casos investigados, 12 registram atuação como professores e/ou educadores de escolas, seminários, institutos de pesquisa, faculdades e universidades. Desta soma específica, 3/12 apresentam registros como educadores, sendo dois atuantes nas Comunidades Eclesiais de Base (CEBs) ${ }^{5}$ de suas respectivas regiões, identificados como "educadores populares”, e um com participação marcante em escolas das séries iniciais do ensino fundamental no interior do estado.

Do montante dos casos que atuaram como professores de formação superior (9/12), observa-se uma certa equivalência entre os que lecionaram no âmbito de formação seminarística e os que atuaram em faculdades e na universidade; $4 / 9$ se dedicaram ao magistério no Seminário de Santo Antônio ${ }^{6}$, principal local de formação de padres do Maranhão, com sede na capital São Luís; e 5/9 exerceram a função de professores universitários e/ou de institutos de pesquisa. Nota-se que a incidência de agentes que transitam no espaço de ensino superior é bastante significativa, o que oferece pistas sobre os tipos de produção escrita aos quais se dedicaram, tais como artigos (de cunho religioso ou não) e pesquisas científicas publicadas em livros, o que se observará mais adiante.

Dos que atuaram nessa esfera de produção de conhecimento, 3 alcançaram o ápice da hierarquia administrativa das instituições de ensino superior onde lecionaram, sendo: um fundador da Escola de Antropologia Aplicada à Distância em São Luís; um reitor do Seminário de Santo Antônio, entre os anos de 1989 e 1994; e um diretor da Faculdade de Filosofia do Maranhão, em 1957. Este foi o caso do cônego Ribamar Carvalho, o mesmo que, alguns anos depois, assumiria a reitoria da Universidade Federal do Maranhão (1968-1972).

0 comando de instituições de ensino no Maranhão, do primário ao nível superior, sob a batuta de agentes católicos evidencia a tentativa da Igreja de controlar e manter sua influência sobre a produção cultural e a formação educacional no país como um todo. Isso se coaduna com o predomínio exercido historicamente pela instituição eclesiástica no Brasil, particularmente em duas esferas

cultura e educação quando os estudos iniciais e secundários eram promovidos e geridos pela Igreja e as interpretações sobre a história do país eram produzidas por padres (MICELI, 2009; PACHECO, 1969).

No Maranhão, isso não foi diferente. Mesmo após a laicização promovida pelo advento da República, a Igreja continuou disputando o controle ideológico do ensino junto ao Estado. A partir da década de 1930, as disputas se arrefecem quando são criadas, em âmbito local, a Juventude Universitária

5. São comunidades formadas especialmente por leigos e leigas, circunscritas a um espaço territorial, responsáveis por atividades de evangelização (organização de ministérios, festejos, etc.) de forma participativa e colegiada, envolvendo as populações locais. Para outras informações sobre as Cebs, consultar Salem (1981).

6. 0 Seminário diocesano de Santo Antônio foi fundado em 1838, durante o bispado de D. Marcos Antonio de Sousa (1827-1842). 0 Seminário tinha por função iniciar os futuros padres recrutados junto às elites maranhenses nos estudos da fé e da doutrina cristã, ofertando-lhes uma formação educacional religiosa, moral e literária. Com o tempo, tornou-se o único Seminário no Maranhão dedicado exclusivamente à formação do sacerdócio (PACHECO, 1969, p. 155). 
Católica e a Ação Universitária Católica, que a nível nacional estavam direcionadas para o recrutamento das futuras elites representadas pelos universitários (RIDENTI, 2002, p. 22). A nível regional, este processo acabou desembocando na fundação da Universidade Federal do Maranhão, onde se registrou a participação efetiva de membros da hierarquia eclesiástica que comandavam a Arquidiocese de São Luís e dos literatos que integravam a Academia Maranhense de Letras (FARIA; MONTENEGRO, 2005, p. 18-19).

Concomitante a isso, a expansão da influência da Igreja sobre o ensino universitário se corporifica na inserção de sacerdotes nas demais instituições de letrados no Maranhão, ao passo que sinaliza para o desenvolvimento de um corpo de intelectuais e lideranças católicas constituídos para pautar e animar os debates em defesa dos pressupostos do catolicismo na esfera pública brasileira (MAINWARING, 2004; CORADINI, 2012). Tais ações evocam um esforço da Igreja em ocupar posições estratégicas em áreas tidas como fundamentais para a manutenção de seu poder simbólico junto à sociedade, como a produção cultural e o sistema de ensino (primário, secundário e superior), num processo chamado por Sérgio Miceli (2009, p. 29) de "enquadramento institucional dos intelectuais”.

Destaca-se ainda a atuação de poetas (3), ensaístas (3), romancistas (3) e teatrólogos (2), o que implica numa observação de forte atuação de padres no cenário cultural do estado, como produtores e/ou intérpretes da história e da cultura. Pertencer às instâncias de reconhecimento acadêmico, portanto, conferia crédito social às representações produzidas pelos agentes da Igreja sobre a política, a cultura, a história e a sociedade maranhense (MELO, 2013, p. 153).
Cabe destacar ainda que outras profissões apresentam alguma recorrência entre os casos arrolados são a de jornalista (3/14) e a de advogado (2/14). Pontualmente, aparecem registros de padres que atuaram como médico (1) e militar (1), e que, eventualmente, participaram também da esfera político-partidária, o que evidencia a hibridização de suas atividades sacerdotais, imiscuídas com funções e formações mundanas, por assim dizer, que compõem a heterogeneidade de seu ofício religioso.

No caso da profissão de médico, este foi exercido anteriormente ao ingresso no sacerdócio por João Mohana, que clinicou e participou de diversos movimentos e campanhas de saúde em São Luís. 0 caso do registro de militar trata-se de Xavier Gilles, que combateu pelo exército francês na Guerra de Independência da Argélia (1956). A atuação de "padre político" fora identificada no itinerário de Clodomir Brandt e Silva, que liderou um grupo de oposição aos defensores de Vitorino Freire no município de Arari. Eleito três vezes vereador, padre Brandt apoiou uma candidatura que venceu as eleições para a prefeitura daquela cidade (FERNANDES, 2012, p. 56), tornando-se assim "líder político” e religioso num espaço geográfico dominado por disputas faccionais entre famílias "tradicionais" de políticos.

No tocante aos clérigos que tiveram suas funções identificadas apenas no âmbito confessional, destaca-se o registro de sua participação como "militantes" em associações de moradores e comunidades eclesiais de base, e que fizeram de seu ofício sacerdotal o sentido maior de suas vidas. Sua experiência profissional, no entanto, é registrada apenas no âmbito das instituições engajadas da Igreja, com destaque para a 
$\mathrm{CPT}^{7}$. Os dois casos foram coordenadores da instituição em Goiás (1979) e no Maranhão (1982). São eles, respectivamente, os padres Josimo Tavares e Cláudio Bergamashi. Observa-se ainda que nenhum dos dois possui registro de inscrição em instâncias de consagração intelectual, nem universitária e nem de letrados, o que não impede que sejam percebidos e se percebam como tal. Seu reconhecimento, neste caso, surge dos usos sociais que fizeram da atividade da escrita (artigos para jornais, panfletos, manifestos) como instrumento de luta política nos espaços em que atuaram na defesa de suas causas e da Igreja.

De um modo geral, tais registros indicam que a propensão dos agentes em se dedicar ao exercício de escrever está indissociavelmente ligada às atividades que exerceram ao longo de suas carreiras, haja vista que todas elas engendram a escrita como ferramenta indispensável e presente em suas rotinas de trabalho. Em outras palavras, o fato de padres produzirem bens culturais (notadamente livros), de cunho caritativo e de engajamento social, provém da aquisição da habilidade da escrita legatária de sua formação religiosa e reforçada a partir de suas múltiplas inserções em espaços sociais de valorização do exercício de escrever como recurso distintivo de atuação evangelizadora.

Essa, aliás, é outra característica interessante a ser ressaltada: a de pertencimento ou de inscrição dos agentes investigados em instâncias de consagração intelectual, além do âmbito universitário, especialmente como integrantes de agremiações literárias. Dos casos analisados, 5/14 se enquadram nesse tipo de reconhecimento intelectual, constando como membros efetivos e/ou "pais fundadores" de academias de letras espalhadas pelo Maranhão. Destes 5 casos, 3 são membros da Academia Maranhense de Letras (AML), com sede na capital São Luís, e os outros 2 são pertencentes a instâncias de letrados no interior do estado, sendo um da Academia Vianense, onde ocupa a Cadeira $n^{\circ}$ 2, e um da Academia Imperatrizense, da qual consta como fundador e primeiro presidente.

Cabe ainda pontuar os trânsitos realizados pelos agentes em outros espaços de socialização, cujas relações propiciaram a aquisição de disposições e de saberes práticos reconvertidos para uma esfera de atuação militante e de disputas políticas pela conquista e/ou manutenção de posições dentro de um espaço de poder mais amplo. Alguns desses espaços são marcados pela presença de organizações e instituições vinculadas à Igreja, como a Comissão Pastoral da Terra (CPT), o Conselho Indigenista Missionário (CIMI), a regional da Cáritas no Maranhão, a Associação de Saúde da Periferia (ASP), entre outros, além dos movimentos promovidos, gestados e geridos por membros da hierarquia eclesiástica, como a Ação Católica no estado, e os movimentos da juventude, com suas ramificações em diversos domínios, especialmente no mun-

7. A Comissão Pastoral da Terra (CPT) foi instituída no Maranhão em 1975 como parte de um intenso programa de ação social junto às populações rurais por parte da Igreja. Dentre os principais objetivos da CPT no Maranhão, destaca-se a tentativa da Igreja de fazer frente ao crescimento dos conflitos no campo, promovendo assim a organização dos trabalhadores rurais na condução de suas lutas pela conquista de direitos sociais. 
do agrário (JAC), no âmbito do operariado (JOC) e na esfera universitária (JUC) . $^{8}$

Sobre esse aspecto, observa-se a presença de padres (6/14) atuando como assessores e formadores de lideranças da juventude católica em suas distintas ramificações, particularmente na JIC (1), na JOC (3) e na JUC (3), sendo um deles com acúmulo de experiências nas três esferas - o cônego Ribamar Carvalho. No que se refere especificamente ao âmbito de atuação da JUC, os três casos identificados exercem funções de assistentes e de formadores de lideranças. São eles Hélio Maranhão, João Mohana e Ribamar Carvalho. Estes três casos são representativos do tipo de intervenção política realizada pelos “intelectuais católicos" no Maranhão, muito mais próximos do centro de poder e da alta hierarquia da Igreja.

Como é sabido, os membros da JUC estavam diretamente ligados a inúmeras ações políticas no estado no período abordado, principalmente no que tange ao engajamento político em sindicatos e associações, à organização de movimentos, passeatas, protestos, apoio a greves, reivindicação por políticas públicas, tais como o Movimento Contra a Carestia, que nasceu na seara das atividades desenvolvidas pelas CEBs (BORGES, 1998, p. 80-81). 0 perfil dos três agentes que trabalhavam com formação de líderes católicos no âmbito da juventude universitária corresponde aos tipos de investimentos (mais ou menos conscientes) realizados em sua formação escolar e ao prestígio social obtido por seu reconhecimento intelectual. Ao estabelecerem-se como mediadores das relações políticas entre o público acadêmico e os órgãos de Estado, acabam por garantir a manutenção de suas posições de poder perante seus representados.

Além desses casos específicos, 5/14 dos sacerdotes apresentam registros de atuação na organização e execução das atividades das CEBs, tanto na capital (3) quanto no interior (2), ocupando posições de "lideranças" e de "porta-vozes" no seio das comunidades onde atuam. No que se refere ao trânsito em instituições de perfil engajado, observa-se o registro de 7/14 dos casos investigados que atuaram como fundadores e/ou coordenadores da CPT (6) e do CIMI (1) no estado, exercendo ainda outras funções burocráticas das mesmas instâncias como advogados, jornalistas, assessores teológicos e educacionais. Pontua-se ainda a passagem de sacerdotes pelo âmbito administrativo de outras instituições correlatas quanto ao perfil de "porta-vozes de causas legítimas", como diretor da Cáritas (1), assistente da Associação da Saúde da Periferia - ASP (1) e presidente do Instituto de Colonização de Terras no Maranhão Iterma (1).

No tocante à participação na esfera das instituições políticas e de postos administrativos de governo, 5/14 registram ocupação de cargos e funções em órgãos distintos, sendo 1 Secretário de Governo de

8. 0 surgimento da JAC, JEC, JIC, JOC e JUC é um esforço da Ação Católica Brasileira em promover a renovação das práticas pastorais na Igreja, com foco especial nos movimentos de juventude, numa tentativa de cooptar futuros quadros e líderes católicos junto a setores específicos da sociedade. Conforme assinala Salem (1981, p. 22), “o primeiro grupo 'especializado' que se constitui é a Juventude Operária Católica (JOC). Em 1950, funda-se a JAC (Juventude Agrária), a JEC (Juventude Estudantil, composta por estudantes secundaristas), JUC (Juventude Universitária) e JIC (Juventude Independente), agrupando os que não se encaixavam nas outras categorias”. 
Newton Bello, 1 Chefe de Gabinete na Prefeitura de Balsas-MA (1995-2000) e também consultor da Secretaria de Segurança do Governo Jackson Lago (2007-2009), 1 presidente do Iterma (1982), e 1 membro do Conselho de Assistência Social do Maranhão e assistente da ASP. Tais registros evidenciam a tendência da heteronomia da carreira de religiosos católicos no estado, apontando também para a fluidez, cada vez maior, das invisíveis fronteiras e da forte imbricação entre os distintos domínios da religião, da cultura e da política.

\section{Gêneros de escrita e recursos culturais}

Não se pode negar que o ato de escrever implica num trunfo distintivo do escritor no espaço de concorrência pela produção de bens simbólicos, visto que a escrita ocupa posição de excelência nas sociedades de letrados. No tocante ao âmbito religioso, o sacerdote que escreve faz uso dessa atividade intelectual tanto como meio de expressar uma visão eclesiástica sobre 0 mundo social, concorrendo assim com os intelectuais profanos, não enquadrados institucionalmente, como também um instrumento de luta política pela ocupação e manutenção de postos, posições e consecução de projetos.

Pode-se mesmo dizer que, numa região periférica em que poucos têm acesso à educação e o exercício da escrita é valorizado como principal atividade intelectual entre as elites, quem escreve e publica livros não apenas registra seu nome e suas ações na história, mas também demarca sua posição de poder perante os demais concorrentes. De modo geral, aqueles que atuam como mediadores culturais consubstanciam suas posições, disposições e posicionamentos na publicação de textos, especialmente de livros, legitimando assim a manutenção do próprio papel social que assumem em diferentes momentos e domínios.

Com foco nesta perspectiva, passa-se à identificação dos gêneros de escrita aos quais os agentes dedicaram-se com maior incidência, numa tentativa de correlacioná-los às posições que ocuparam ao longo de seus trajetos de vida. 0 objetivo é demonstrar que o grau de concentração dos escritos e das temáticas abordadas está irremediavelmente conectado aos recursos acumulados (saberes, habilidades, conhecimento) e às experiências vividas (cargos, atividades, funções, profissões).

Quadro 3 - Frequência das modalidades de escrita

\begin{tabular}{|l|c|c|}
\hline Gêneros & Quantidade & \% \\
\hline Religiosidade & 28 & 23,7 \\
\hline Generalista & 38 & 32,2 \\
\hline Literatura & 24 & 20,3 \\
\hline Memórias & 6 & 5,08 \\
\hline Não-classificados & 22 & 18,6 \\
\hline Total & 118 & $100 \%$ \\
\hline
\end{tabular}

Fonte: Dados coletados de fontes diversas. 
Dessa forma, procedeu-se à explicitação dos gêneros de escrita baseados nos tipos de escritos que aparecem com maior recorrência: religiosidade (textos teológicos e doutrinários, que versem sobre orações, salmos, exaltação à fé cristã, espiritualidade); generalista (artigos jornalísticos, escritos de militância, concepções sobre história, cultura, política, sociedade, comportamento, família, casamento, sexualidade etc.); literários (romances, peças de teatro, contos, crônicas e poesias); além dos textos memorialísticos, incluindo-se as autobiografias. Os demais livros não inclusos nesta taxonomia, devido às poucas recorrências evidenciadas, foram listados como "nãoclassificados".

Dos dados levantados sobre a produção intelectual dos 14 casos investigados, verificaram-se algumas frequências de determinadas temáticas e tipos de escrita, tais como trabalhos de ordem técnica, que ensejam saberes específicos, particularmente na esfera acadêmico/científica. Além destes, evidentemente, observam-se textos de cunho religioso, voltado para a doutrina e a disseminação do evangelho, e escritos de militância, destinados à mobilização social e intervenção nos diferentes domínios. Há ainda textos ideológicos, de caráter mais contemplativo e filosófico, que expressam "projetos" de sociedade, visões de mundo, paixões, noções e ideologias; produções literárias (romances, peças de teatro, contos, crônicas e poesias); memórias e autobiografias; e até mesmo textos manualísticos, de caráter psicológico, com vistas à orientação da sexualidade e do comportamento de jovens e adultos.

A ordenação por gêneros das obras catalogadas revela uma variedade de usos da escrita em seus diferentes formatos, e as estratégias ativadas através dos recursos dis- poníveis de cada agente para legitimação de seus textos. Observa-se, assim, que dos 14 casos investigados há uma incidência de 38 títulos $(32,2 \%)$ publicados dentro da classificação de textos generalistas, isto é, textos escritos sobre diversas áreas e assuntos. A categoria de publicações religiosas registra frequência de 28 casos (23,7\%): 24 registros $(20,3 \%)$ são de textos literários e apenas 6 casos $(5,08 \%)$ trata-se de memórias e autobiografias. Dos livros não inseridos em nenhuma dessas classificações, constam 22 títulos (18,6\%).

As frequências apresentadas fornecem alguns indicadores sobre a tendência de consolidação do gênero generalista, que não necessariamente enseja a ativação de saberes e conhecimentos técnicos especializados, mas antes a explicitação de habilidades de escrita, maior nível de leitura de um modo geral e de um certo grau de "politização” perante os assuntos temporais. Em seu conjunto, tais indicadores evidenciam uma tomada de conscientização e de posição associadas a uma incidência maior de posicionamentos engajados sobre questões de cunho histórico, filosófico, político, cultural, psicológico, social, ideológico.

Por outro lado, percebe-se que mesmo diante da prevalência de escritos mais gerais, assuntos da esfera religiosa ocupam o segundo lugar com uma diferença não tão ampla assim (apenas 8,5\%). Ocorre ainda que o gênero religiosidade também ocupa uma posição de proximidade com o gênero literário, havendo assim certo paralelismo entre investimentos feitos pelos agentes clericais em escritos de vertente mais religiosa e literária, ambos correspondendo a 23,7\% e 20,3\%, respectivamente. Dos casos analisados, pontua-se ainda uma tendência na redução de textos memorialísticos, que registraram o percentual de 5,08\%. 
A tendência geral parece ser a de que sacerdotes dedicados a temáticas religiosas buscam ampliar sua clientela por meio da produção de textos mais generalistas, em consonância com as demais atividades que exercem para além da confessional. A ampliação das lentes clericais sobre o mundo social encontra no gênero da generalidade um nicho cativo, tanto para a demarcação de concepções e ideologias que visam a "salvação das almas" por meios mais heterodoxos, quanto pelo desejo em (re)afirmar sua condição de intelectual legitimado pela Igreja, pela formação acadêmica e pelas múltiplas experiências sociais adquiridas em seus itinerários.

Dedicar-se à atividade da escrita e à publicação de livros sobre temáticas diversas, mas a partir do ponto de vista da Igreja, coaduna a edificação e imbricação de perfis, tanto do intelectual quanto do sacerdote socialmente legitimado. A voz sacerdotal duplamente autorizada, pela instituição eclesiástica e pelo mundo social, condiciona a complexifıcação da atividade sacerdotal por meio da exigência da aquisição de capitais raros e distintivos, além da reconversão de recursos sociais de origem e de percurso de vida como variáveis que medeiam a disputa travada no espaço de concorrência mais geral pelo monopólio da produção legítima de bens culturais no Maranhão.

\section{Considerações finais}

Compreende-se, portanto, que o perfil geral dos padres que se dedicam à atividade da escrita no Maranhão é bastante heterogêneo e multifacetado, correspondendo assim a um maior grau de hibridização da atividade sacerdotal. Em geral, são padres que se diferenciaram dos demais agentes no espaço de concorrência pelo itinerário ocupacional multifacetado e pelo acúmulo de títulos escolares raros (principalmente de formação superior em outras áreas distintas das tradicionais - teologia e filosofia), cujos saberes foram acionados em momentos oportunos na demarcação de posições estratégicas e na confecção de posicionamentos sobre o mundo social, evidenciado na publicação de seus escritos em formato de livros.

Desse modo, sacerdotes que escrevem e que tiveram acesso a canais de divulgação de seus escritos, aliado à obtenção de capitais, saberes e competências específicas para além do âmbito confessional, estão enredados por teias sociais que remetem desde a inserção em círculos sociais privilegiados ao pertencimento a novos espaços de socialização de letrados, onde a habilidade da escrita é um trunfo bastante valorizado. Nesse sentido, os usos sociais da escrita por sacerdotes maranhenses são exemplos distintivos dos poderes simbólicos que incidem sobre a produção de livros de "intelectuais católicos", acionada como trunfo não apenas para demarcar posições e adotar posicionamentos, mas efetivamente como trincheira de luta pela imposição de representações legítimas sobre o mundo social.

Se, de um lado, os condicionantes que constrangeram e favoreceram uma multiplicidade de intervenções no mundo social - ampliando e diversificando o leque de atuação de sacerdotes e legitimando processos e ações em espaços não necessariamente de cunho confessional -, são entrecortados por transformações históricas e institucionais, nem sempre operadas em conjunto, por outro lado as formas e modalidades de mediação (cultural, política, social, religiosa) escolhidas pelos agentes, muitas vezes, parecem ter bases motivacionais próximas entre si, apesar 
de também preservarem suas peculiaridades e pontos dissonantes.

Em última análise, a diversificação das modalidades de atuação sacerdotal que transita por distintos domínios sociais, particularmente nas esferas da política e da cultura, orbitando em torno das elites e dos grupos dirigentes locais, acaba por mesclar também elementos políticos-ideológicos que fornecem um repertório discursivo voltado para a realização de práticas heterodoxas de evangelização que, em seu conjunto, evidenciam o grau de hibridização do ofício de sacerdote no Maranhão.

\section{Referências}

AZZI, R. Presença da Igreja na sociedade brasileira e formação das dioceses no período republicano. In: SOUZA, R. L.; OTTO, C. (Orgs.). Faces do Catolicismo. Florianópolis: Insular, 2008.

BE0ZZO, J. 0. A Igreja do Brasil no Concílio Vaticano II (1959-1965). São Paulo: Paulinas, 2005.

BORGES, A. S. A construção do Partido dos Trabalhadores no Maranhão. São Paulo: Ed.Unesp, 1998.

BOURDIEU, P. A economia das trocas linguísticas: o que falar quer dizer. 2. ed. São Paulo: Edusp, 2008.

Coisas ditas. São Paulo: Brasiliense, $2004 a$

- Homo academicus. Florianópolis: Ed. UFSC, 2011.

. Os usos sociais da ciência: por uma sociologia clínica do campo científico. São Paulo: Ed. Unesp, 2004b.

CORADINI, 0. L. As missões da "cultura” e da "política": confrontos e reconversões de elites culturais e políticas no Rio Grande do Sul (1920-1960). Revista de Estudos Históricos, Rio de Janeiro, n. 32, p. 125-144, 2003.
. Os usos das ciências humanas e sociais pelo catolicismo e pelo luteranismo e as relações centro/ periferia. Dossiê: Cultura, poder e modalidades de engajamento. Revista Pós Ciências Sociais - Repocs, São Luís: Edufma, v. 9, n. 17, p. 67-99, 2012.

FARIA, R. H. M.; MONTENEGRO, A. T. (Orgs.). Memória de professores: histórias da Ufma e outras histórias. São Luís: Universidade Federal do Maranhão/Departamento de História; Brasília: CNPq, 2005.

FERNANDES, J. 0 universo do Padre Brandt. São Luis: Unigraf, 2012.

GRILL, I. G.; REIS, E. T. 0 que escrever quer dizer na política? Carreiras políticas e gêneros de produção escrita. Dossiê: Cultura, poder e modalidades de engajamento. Revista Pós Ciências Sociais - Repocs, São Luís: Edufma, v. 9, n. 17, p. 101-121, 2012.

MACHADO, J. L. F. Ação política, missão pastoral e instâncias de inserção: engajamento de clérigos no Maranhão (1970-1980). 2012. 160f. Dissertação (Mestrado em Ciências Sociais) - Universidade Federal do Maranhão, São Luís, 2012.

MAINWARING, S. Igreja Católica e política no Brasil. São Paulo: Brasiliense, 2004.

MELO, H. F. de. Entre rosas e armas: atuação política da Igreja Católica e ditadura militar no Maranhão (1968-1974). 90 f. Monografia (Graduação em História) - Universidade Estadual do Maranhão, São Luís, 2010.

. O ofício de sacerdote: mediação cultural, atuação política e produção intelectual de padres no Maranhão. 2013. 190f. Dissertação (Mestrado em Ciências Sociais) - Universidade Federal do Maranhão, São Luís, 2013.

MICELI, S. A elite eclesiástica brasileira. São Paulo: Companhia das Letras, 2009.

PÉCAUT, Daniel. Os intelectuais e a política no Brasil: entre o povo e a nação. São Paulo: Ática, 1990.

PEREIRA, J. M. Engajamento militante e a "luta pela moradia em São Luís” entre as décadas de 
1970 e 1980. 2011. 201 f. Dissertação (Mestrado em Ciências Sociais) - Universidade Federal do Maranhão. São Luís, 2011.

PACHECO, D. F. C. História eclesiástica do Maranhão. São Luís: Departamento de Cultura do Estado, 1969.

REIS, E. T. R. Em nome da "cultura": porta-vozes, mediação e referenciais de políticas públicas no Maranhão. Revista Sociedade e Estado, v. 25, n. 3, set./dez. 2010.

REVISTA PÓS CIÊNCIAS SOCIAIS - REPOCS. Cultura, poder e modalidades de engajamento (Dossiê). Universidade Federal do Maranhão, Programa de Pós-graduação em Ciências Sociais. São Luís: Edufma, v. 9, n. 17, 2012.

RIDENTI, M. “Ação Popular: cristianismo e marxismo”. In: REIS FILHO, D. A.; RIDENTI, M. (Orgs.). História do marxismo no Brasil: partidos e organizações dos anos 20 aos 60. Campinas: Ed. Unicamp, 2002. p. 213-282.

SAPIRO, G. Modelos de intervenção política dos intelectuais: o caso francês. Dossiê: Cultura, poder e modalidades de engajamento. Revista Pós Ciências Sociais - Repocs, São Luís: Edufma, v. 9, n. 17, p. 19-50, 2012.
SALEM, Helena (org.). A Igreja dos oprimidos. São Paulo: Ed. Brasil Debates, 1981.

SEIDL, E. Intérpretes da história e da cultura: carreiras religiosas e mediação cultural no Rio Grande do Sul. Revista Anos 90, Porto Alegre, v. 14, n. 26, p. 77-110, dez. 2007.

SERRY, H. Literatura e catolicismo na França (1880-1914): contribuição a uma sócio- história da crença. Tempo Social: revista de sociologia da Usp. São Paulo, v. 16, n. 1, p. 129-152, 2004.

SIGAL, S. Intelectuais, cultura e política na Argentina. Dossiê: Cultura, poder e modalidades de engajamento. Revista Pós Ciências Sociais - Repocs, São Luís: Edufma, v. 9, n. 17, p. 51-66, 2012.

SIMIONI, A. P. C. Profissão artista: pintoras e escultoras acadêmicas brasileiras. São Paulo: Edusp; Fapesp, 2008.

SORÁ, G. Brasilianas: José Olympio e a gênese do mercado editorial brasileiro. São Paulo: Edusp: Com-Arte, 2010. 
RESUMO

Análise dos condicionantes que presidiram a intervenção multifacetada de agentes católicos em distintas esferas sociais, particularmente no âmbito da política e da cultura no Maranhão, entre os anos de 1950 e 1980. Focaliza-se a atuação de padres enquanto mediadores culturais e porta-vozes de demandas sociais em consonância com o exercício de seu ofício sacerdotal. A partir do mapeamento de sua produção escrita e da recomposição de seus itinerários, foram investigados 14 agentes cujo exame de suas propriedades sociais e recursos culturais permitiu (i) a explicitação de determinados perfis de religiosos que se dedicaram à escrita, (ii) a composição de um repertório híbrido da atividade sacerdotal e (iii) o desnudamento dos poderes sociais que engendram a produção intelectual de clérigos. Os resultados apontaram para o entrecruzamento de lógicas distintas de engajamento de sacerdotes, imiscuídas no processo de mutação dos condicionantes institucionais eclesiásticos e de (re)definição dos papéis religiosos.

\section{PALAVRAS-CHAVE}

Igreja católica. Sacerdotes. Mutação institucional. Papéis religiosos. Produção intelectual.

\section{ABSTRACT}

Analysis of the factors that presided over the multifaceted intervention of catholic agents in different social spheres, particularly in the context of politics and culture in Maranhão, between the years of 1950 and 1980. Focuses on the role of priests as cultural mediators and spokespersons of social demands in consonance with the exercise of their priestly office. From the mapping of its written production and the recomposition of yours itineraries, 14 agents whose examination of their social properties and cultural resources (i) the clarification of certain religious profiles dedicated to writing, (ii) the composition of a hybrid repertoire of priestly activity, and (iii) the denudating of the social powers that engender the intellectual production of clerics. The results pointed to the intertwining of distinct logics of priests engagement, immersed in the process of mutation of ecclesiastical institutional constraints and (re) definition of religious roles.

\section{KEYWORDS}

Catholic Church; Priests; Institutional mutation; Religious roles; Intellectual Production. 
